\title{
Characteristics of residual organochlorine pesticides in soils under different land-use types on a coastal plain of the Yellow River Delta
}

\author{
Yuan Li • Haibo Zhang • Qingbo Li - Qian Zhou • \\ Xiaobing Chen $\cdot$ Chen Tu $\cdot$ Yongming Luo Peter Christie • \\ Xuefeng $\mathrm{Hu} \cdot$ Lianzhen Li
}

Received: 12 March 2015/ Accepted: 16 June 2015

(C) Springer Science+Business Media Dordrecht 2015

\begin{abstract}
The residual levels of organochlorine pesticides (OCPs) were examined in soils covering five types of land use along a salinity gradient on the Yellow River Delta. The most prominent OCPs were dichlorodiphenyltrichloroethane $\left(\sum \mathrm{DDT}\right.$, arithmetic mean $=5.11 \mu \mathrm{g}$ $\left.\mathrm{kg}^{-1}\right)$, hexachlorocyclohexane ( $\sum \mathrm{HCH}, 1.69 \mu \mathrm{g} \mathrm{kg}^{-1}$ ) and $\sum$ endosulfan $\left(10.4 \mu \mathrm{g} \mathrm{kg}^{-1}\right)$. The spatial variability of OCPs composition shifted from $\gamma$-HCH and $o, p^{\prime}$-DDT dominated pesticides in coastal soils to $p, p^{\prime}$-DDE dominated pesticides in inland soils. In different land-use types, the percentages of $\beta-\mathrm{HCH}$ and $p, p^{\prime}$-DDE are characterized by more recalcitrant components in decreasing order of vegetable fields, cereal fields, cotton fields, wetlands and tidal flats with increasing soil
\end{abstract}

Yuan Li and Haibo Zhang have contributed equally to this work.

Electronic supplementary material The online version of this article (doi:10.1007/s10653-015-9738-4) contains supplementary material, which is available to authorized users.

Y. Li $\cdot$ H. Zhang $\cdot$ Q. Zhou $\cdot$ X. Chen ·

C. Tu $\cdot$ Y. Luo $(\bowtie) \cdot$ X. Hu $\cdot$ L. Li

Key Laboratory of Coastal Environmental Processes and Ecological Remediation, Yantai Institute of Coastal Zone Research, Chinese Academy of Sciences, Yantai 264003, China

e-mail: ymluo@yic.ac.cn

Y. Li - H. Zhang - Q. Zhou - X. Chen - Y. Luo - X. Hu University of Chinese Academy of Sciences,

Beijing 100049, China salinity. However, the less recalcitrant components, $\gamma$ $\mathrm{HCH}$ and $o, p^{\prime}$-DDT, showed an opposite trend. Endosulfan sulfate predominated in all land-use types. Residual levels of $\beta-\mathrm{HCH}$ were affected by soil organic matter. The correlations between $\gamma-\mathrm{HCH}$ and clay content and between $p, p^{\prime}$-DDE, $o, p^{\prime}$-DDT and salinity might associate with the influence of sediment cotransport by the Yellow River and the density of anthropogenic activities in coastal region. Depth distribution of the OCPs in typical soil profiles also implied that local historical usage and sediment transport by the Yellow River both affected the OCPs residual in this region.

Keywords Yellow River Delta - Coastal zone · Land-use types · Organochlorine pesticides · Salinity gradient

Q. Li

College of Environmental Science and Engineering,

Dalian Maritime University, Dalian 116026, China

P. Christie

Agri-Food and Biosciences Institute, Newforge Lane, Belfast BT9 5PX, UK 


\section{Introduction}

Organochlorine pesticides (OCPs) such as dichlorodiphenyltrichloroethane (DDT) and hexachlorocyclohexane $(\mathrm{HCH})$ are characterized by toxicity, stability and recalcitrance to degradation in natural environments and are of worldwide concern. They have been found in a wide range of environmental media throughout the world since 1960s reported firstly (Iwata et al. 1994). Soil is an important reservoir for OCPs and plays an important role in their distribution and environmental fate. Residual levels and environmental behavior of OCPs in soils are a complex function of the balance between inputs and losses, and these were determined by agricultural practices such as cultivation history and flood irrigation and soil properties such as pH and organic matter (Boul et al. 1994; Zhang et al. 2006, 2012a; Gao et al. 2013). Land-use types can reflect the variation in agricultural activities and soil conditions and consequently affect the OCP residues in soils. Munn and Gruber (1997) found that upstream soil erosion might be an important factor to control the residual levels of DDTs in the irrigated agricultural soils of downstream area. Yu et al. (2013) reported that residual levels of HCHs and DDTs varied spatially with land-use types due to the variation in soil properties. In coastal regions, river sediments and salt ions also contribute greatly to the distribution and degradation of organochlorine pollutants. Lee et al. (2001) found that silt and clay in sediments of coastal regions were the dominant factors in the retention of HCHs. Cho and Oh (2005) reported the inhibition of dechlorination of PCBs in lower Hudson River sediments in the USA with high sulfate concentrations due to the suppression of the growth of methanogens.

Organochlorine pesticides including DDTs and $\mathrm{HCHs}$ were extensively used in paddy field and cotton field in China (Wong et al. 2005). Although application of technical HCH and DDT has been banned in China since 1983, their residues were still detected ubiquitously with a high level in the coastal soils of the Haihe Plain, the Yangtze River Delta and the Pearl River Delta (Tao et al. 2008; Zhang et al. 2009; Yu et al. 2013). Fresh inputs of HCHs and DDTs in soils were also identified, which were assumed to be sourced from the usage of lindane, dicofol and DDTcontaining antifouling paints (Qiu et al. 2005; Wei et al. 2007). Endosulfan, a type of organochlorine pesticide in use currently, has been applied to control pests in cotton wheat, tea, tobacco, apple and other fruits in China since 1994 (Jia et al. 2009). The extensive application of endosulfan has contributed to a high residual level in the soils of the eastern coastal farmland of China (Jia et al. 2010; Zhang et al. 2012b).

The Yellow River Delta, one of China's three major river deltas, was scheduled by the State Council of China to be developed into a large ecological and economic region. The delta has been undergoing rapid development of chemical industry and agriculture, which could produce large amounts of new organic pollutants in addition to the residue of formerly applied chemicals. However, limited studies have been conducted on organochlorine pollutants in this area which were mainly connected with residual levels in the sediments and the birds of the estuary (Da et al. 2013, 2014; Gao et al. 2009). To our knowledge, no studies have been reported regarding the impact of land-use type and soil properties such as salinity and clay content on the residue, distribution and sources of organochlorine pollutants on such a coastal plain. The objective of the present study was to examine the impact of land-use types and soil physicochemical properties on the residues of soil OCPs on such a large spatial scale. The study was designed to give a new insight on the fate and possible sources of organochlorine pollutants on the coastal plain.

\section{Materials and methods}

Site description, soil sampling and sample preparation

The Yellow River Delta, one of three major river deltas in China, is situated on the south coast of the Bohai Sea with a temperate, semi-humid continental monsoon climate. The average annual temperature is $11.7-12.6^{\circ} \mathrm{C}$. The average annual precipitation is 530-630 mm, of which $70 \%$ occurs as rainfall during summer (May-July), and the average annual evaporation is 1900-2400 $\mathrm{mm}$ (Zhang et al. 2011a). The crop rotation typically consists of cotton to cereals and then to vegetables. The main soil types are Calcaric Fluvisols (moisture soil), Salic Fluvisols (moist saline soils) and Gleyic Solonchaks (coastal moist saline soils) according to the FAO soil classification (FAO, IUSS Working Group WRB 2007). The alluvial soil is mainly developed on loess material of the quaternary 
period carried by Yellow River from the Loess Plateau. The main crop in the core area of the delta is cotton with limited areas of winter wheat, maize, vegetables and rice. The dotted line in Fig. 1 could divide the delta into newborn land and older land. The right side of the dotted line named as modern Yellow River Delta (mYRD) is a newborn land originating from the shifting of the tail course of the Yellow River from south to north since 1855. The mYRD starts at Ninghai, Shandong Province, and stretches from the Tao'er River in the north to the Zimai River in the south, $97 \%$ of which is located in Dongying City (Zhang et al. 2011a). Half of the water derived from the Yellow River is used for irrigation in the mYRD (Chen et al. 2007).

The spatial distribution of the sampling sites is shown in Fig. 1. Details of their coordinates, land-use types and locations are given in the supplementary material (Table 1S). Twenty-eight surface soil samples $(0-10 \mathrm{~cm})$ at 28 locations were collected across the delta region in November 2012. Approximately $1 \mathrm{~kg}$ samples were taken and mixed from three randomized points in each location using a sample spacing of $10 \mathrm{~m}$. All sampling sites are recorded as vegetable field, cereal field, cotton field, wetland or tidal flat according to land-use type. Due to more than $70 \%$ of the area in the YRD was covered by saline soils (Zhang et al. 2011a), a larger number of cotton as most salt-tolerant crop in this area were sampled than other fields. Horizon samples were collected based on pedogenic features of the soil profile. Twenty-six profile samples from six soil profiles (Y03, Y06, Y10, Y11, Y16 and Y17) in cotton field with 4-5 soil segments were selected to investigate the depth distribution of OCPs. Different profile segments could be combined into four horizons based on depth ranges comprising (1) the surface horizon $(0-20 \mathrm{~cm})$, (2) subsurface horizon $(20-40 \mathrm{~cm})$, (3) middle horizon $(40-70 \mathrm{~cm})$ and (4) basal horizon $(70-120 \mathrm{~cm})$. About $1 \mathrm{~kg}$ samples from each soil horizon were collected using a clean stainless steel spade and were placed in 1-1 brown glass vials. The horizon samples were collected from bottom to the top, and the spade was washed with deionized water prior to next sampling. All the samples were transported to the laboratory and kept at $-20{ }^{\circ} \mathrm{C}$ in a freezer until further treatment. Each sample was divided into two equal parts: one for OCPs analysis ( $250 \mathrm{~g}$ for freeze-drying at $-55{ }^{\circ} \mathrm{C}$ for 1 week) and the other for soil properties analysis ( $250 \mathrm{~g}$ for air-drying at room temperature). The freeze-dried and air-dried samples were crushed to pass through a 10-mesh screen and ground to pass through 60-mesh screen and 100-mesh screen using a mortar and pestle or an agate mill.

Soil $\mathrm{pH} \quad($ water/soil $=2.5 / 1), \quad$ salinity $\quad$ (water/soil $=5 / 1)$ and clay content $(<2 \mu \mathrm{m}$, laser particle analyzer) were determined on the 10 -mesh air-dried
Fig. 1 Locations of sampling sites. The dotted line region shows the modern Yellow River Delta (mYRD). The mYRD is a newborn land originating from the shifting of the tail course of the Yellow River from south to north since 1855. The mYRD starts at Ninghai, Shandong Province, and stretches from the Tao'er River in the north to the Zimai River in the south, $97 \%$ of which is located in Dongying City. Half of the water derived from the Yellow River is used for irrigation in the mYRD

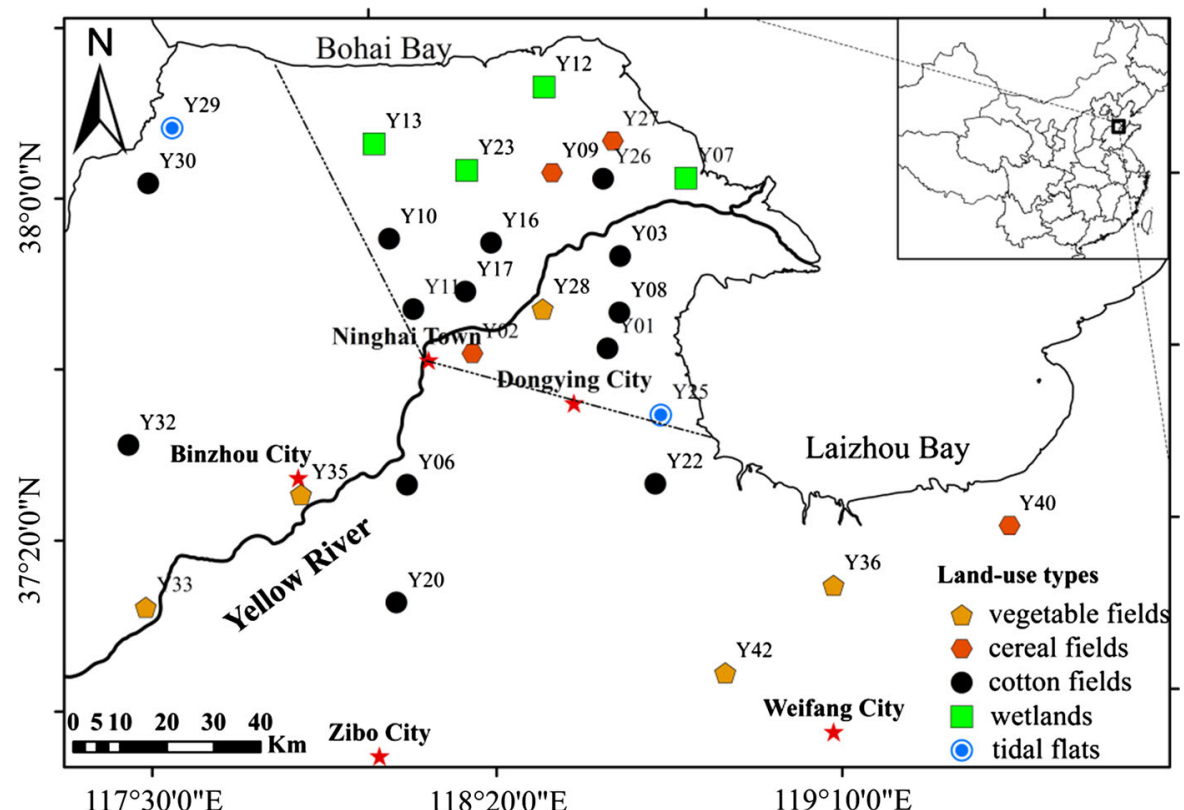


sample. Soil cation exchange capacity (CEC, NaOAc extraction) and soil organic matter (SOM, $\mathrm{K}_{2} \mathrm{Cr}_{2} \mathrm{O}_{7}$ oxidation) were estimated on the 60- and 100-mesh air-dried samples, respectively. Analysis of the soil properties was based on the methods of Lu (1999).

Sample extraction and OCP analysis

All analytical grade solvents (dichloromethane, n-hexane and acetone) used were obtained from Sinopharm Chemical Reagent Co., Shanghai, and distilled prior to use. The anhydrous sodium sulfate $\left(400{ }^{\circ} \mathrm{C}\right.$ for $\left.4 \mathrm{~h}\right)$, $6 \%$ deactivated neutral alumina $\left(300 \mathrm{mesh}, 450{ }^{\circ} \mathrm{C}\right.$ for $16 \mathrm{~h}$ ) and $3.3 \%$ deactivated silica gel (300 mesh, $130{ }^{\circ} \mathrm{C}$ for $16 \mathrm{~h}$ ) were transferred into a column (mass ratio of anhydrous sodium sulfate/neutral alumina/ silica gel $3: 3: 2$ ) to purify the extract. Standard mixtures of $\mathrm{HCB}, \alpha-\mathrm{HCH}, \beta-\mathrm{HCH}, \gamma-\mathrm{HCH}, \delta-\mathrm{HCH}$, $p, p^{\prime}$-DDD $, p, p^{\prime}$-DDE, $p, p^{\prime}$-DDT, $o, p^{\prime}$-DDD, $o, p^{\prime}$-DDE, $o, p^{\prime}$-DDT, $\alpha$-endosulfan, $\beta$-endosulfan, methoxychlor, mirex, heptachlor, heptachlor epoxide, chlordane, dieldrin, endrin and aldrin together with the single standard of endosulfan sulfate were purchased from AccuStandard (New Haven, CT).

Five grams of freeze-dried soil sample $(<250 \mu \mathrm{m})$ was transferred to a pre-extracted glass centrifuge tube and spiked with a recovery standard containing 2,2',4,4',6,6'-hexachlorobiphenyl (PCB 155, AccuStandard, New Haven, CT). Samples were ultrasonic extracted using $20 \mathrm{ml}$ mixed solvent of acetone/nhexane $(1: 1 \mathrm{v} / \mathrm{v})$ for $15 \mathrm{~min}$. The mixture was centrifuged, and the extract was collected. The procedure was then repeated twice, and the extracts were combined. The extracts were concentrated to $1 \mathrm{ml}$ by rotary evaporation and solvent-exchanged into $n$-hexane. The concentrated extracts were cleaned up on the sodium sulfate/neutral alumina/silica gel column (pre-washed with n-hexane) eluting with $30 \mathrm{ml}$ of dichloromethane/n-hexane (v/v 1:1). The effluent was blown down to $1 \mathrm{ml}$ under a gentle stream of nitrogen.

Samples were analyzed with an HP Gas Chromatograph 5890 equipped with an electron capture detector (ECD). A DB35-MS column $(30 \mathrm{~m}$, i.d. $0.25 \mathrm{~mm}$, film thickness $0.25 \mu \mathrm{m}$ ) was used. High-

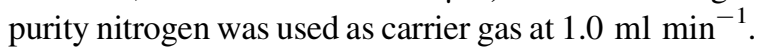
The oven temperature program was as follows: injector and detector temperatures were 240 and $300{ }^{\circ} \mathrm{C}$, respectively, initial run temperature was set at $80^{\circ} \mathrm{C}$ and held for $0.5 \mathrm{~min}$, ramped at $20{ }^{\circ} \mathrm{C} \mathrm{min}-1$ to $200{ }^{\circ} \mathrm{C}$ and held for $1 \mathrm{~min}$, and ramped at $5{ }^{\circ} \mathrm{C} \min ^{-1}$ to $280{ }^{\circ} \mathrm{C}$ and held for $8 \mathrm{~min}$. Peak identification was conducted by comparison with the retention time of each standard $( \pm 0.05 \mathrm{~min})$.

Quality assurance/quality control

Table 1 presents parameters of QA and QC in the analysis of OCPs. The calibration standard solution contained 22 individual OCPs and decachlorobiphenyl (PCB 209) as the internal standard. Six levels of calibration standards $\left(2.0,5.0,10,25\right.$ and $50 \mathrm{ng} \mathrm{ml}^{-1}$ and PCB 209 at a fixed concentration of $25 \mathrm{ng} \mathrm{ml}^{-1}$ ) were used to prepare the calibration curves. The correlation coefficients $(r)$ of calibration curves of OCPs were all higher than 0.99 . The method detection limits (MDL) for the OCPs were determined by 3:1 signal versus noise value $(\mathrm{S} / \mathrm{N})$. For every set of ten samples, procedural blanks, spiked blanks and replicate samples were run to check for interference and cross-contamination. In addition, a surrogate standard was added to each of the samples to monitor procedural performance and matrix effects. The recoveries of surrogate (PCB 155) with which soil samples were spiked ranged from 80.1 to $113.4 \%$, and the relative standard deviation (RSD) values were $<15 \%$.

\section{Statistical analysis}

All statistical analysis was carried out using the SPSS 20.0 for Windows. Concentrations of OCPs in soils were summarized using arithmetic means. The correlations of organochlorines with various soil parameters were analyzed by the Pearson correlation coefficient. A $p$ value of $<0.05$ (two tail) was considered to be statistically significant. Log-transformed data were used to perform normal distribution.

\section{Results and discussion}

Soil properties in the study area

The soil properties are given in Table 2 . The nature of the soils in the delta is sandy, saline and alkaline. The soil salinity sequence was: vegetable fields $<$ cereal fields $<$ cotton fields $<$ wetlands $<$ tidal flats. For agricultural production, the crop cultivation in the 
Table 1 Recovery and method detection limits for the analysis of organochlorine pesticides

\begin{tabular}{|c|c|c|c|c|c|c|c|}
\hline $\begin{array}{l}\text { Organochlorine } \\
\text { pesticide }\end{array}$ & $\begin{array}{l}\text { MDL } \\
\left(\mu \mathrm{kg}^{-1}\right)\end{array}$ & $\begin{array}{l}\text { Recovery } \\
(\%)\end{array}$ & $\begin{array}{l}\text { RSD } \\
(\%)\end{array}$ & $\begin{array}{l}\text { Organochlorine } \\
\text { pesticide }\end{array}$ & $\begin{array}{l}\text { MDL } \\
\left(\mu \mathrm{gg}^{-1}\right)\end{array}$ & $\begin{array}{l}\text { Recovery } \\
(\%)\end{array}$ & $\begin{array}{l}\text { RSD } \\
(\%)\end{array}$ \\
\hline $\mathrm{HCB}$ & 0.20 & 87.3 & 7.0 & $\alpha$-Endosulfan & 0.13 & 93.3 & 4.2 \\
\hline$\alpha-\mathrm{HCH}$ & 0.12 & 95.7 & 10.2 & $\beta$-Endosulfan & 0.26 & 93.2 & 8.5 \\
\hline$\beta-\mathrm{HCH}$ & 0.16 & 81.6 & 13.5 & Endosulfan sulfate & 0.11 & 84.0 & 10.1 \\
\hline$\gamma-\mathrm{HCH}$ & 0.20 & 78.4 & 7.6 & Methoxychlor & 0.08 & 88.0 & 2.8 \\
\hline$\delta-\mathrm{HCH}$ & 0.13 & 89.5 & 4.4 & Mirex & 0.28 & 92.5 & 9.2 \\
\hline$p, p^{\prime}$-DDD & 0.12 & 81.6 & 4.3 & Heptachlor & 0.16 & 82.6 & 5.9 \\
\hline$p, p^{\prime}$-DDE & 0.20 & 86.5 & 10.4 & Heptachlor epoxide & 0.22 & 77.7 & 8.4 \\
\hline$p, p^{\prime}$-DDT & 0.26 & 86.8 & 8.9 & Chlordane & 0.18 & 88.1 & 6.3 \\
\hline$o, p^{\prime}$-DDD & 0.15 & 80.9 & 5.7 & Dieldrin & 0.18 & 75.4 & 12.2 \\
\hline$o, p^{\prime}-\mathrm{DDE}$ & 0.17 & 94.0 & 5.4 & Endrin & 0.17 & 76.0 & 9.2 \\
\hline$o, p^{\prime}$-DDT & 0.22 & 102.3 & 6.5 & & & & \\
\hline
\end{tabular}

Table 2 Main properties of soils in the Yellow River Delta

\begin{tabular}{|c|c|c|c|c|c|c|c|c|c|c|}
\hline \multirow[t]{2}{*}{ Land-use type } & \multicolumn{2}{|c|}{ Salinity $\left(\mathrm{g} \mathrm{kg}^{-1}\right)$} & \multicolumn{2}{|c|}{$\mathrm{CEC}\left(\mathrm{cmol} \mathrm{kg}^{-1}\right)$} & \multicolumn{2}{|c|}{ SOM $(\%)$} & \multicolumn{2}{|c|}{ Clay $(<2 \mu \mathrm{m}, \%)$} & \multicolumn{2}{|l|}{$\mathrm{pH}$} \\
\hline & Mean & Range & Mean & Range & Mean & Range & Mean & Range & Mean & Range \\
\hline Vegetable fields (5) & 0.97 & $0.17-3.66$ & 8.59 & $4.26-15.8$ & 1.54 & $1.08-2.37$ & 6.85 & $3.24-9.04$ & 8.03 & $7.77-8.22$ \\
\hline Cereal fields (4) & 1.63 & $0.08-4.02$ & 9.32 & $4.16-17.7$ & 1.49 & $0.59-2.63$ & 8.66 & $4.92-14.6$ & 7.91 & $7.62-8.16$ \\
\hline Cotton fields (13) & 3.18 & $0.31-8.38$ & 7.72 & $3.77-13.3$ & 1.17 & $0.57-2.09$ & 6.98 & $4.41-10.1$ & 8.00 & $7.80-8.24$ \\
\hline Wetlands (4) & 13.1 & $2.60-20.0$ & 9.40 & $5.46-19.3$ & 2.20 & $0.77-6.01$ & 6.43 & $4.21-8.22$ & 7.98 & $7.90-8.05$ \\
\hline Tidal flats (2) & 18.1 & $10.6-25.5$ & 5.28 & $3.71-6.58$ & 1.11 & $0.82-1.40$ & 5.06 & $4.49-5.63$ & 8.26 & $8.14-8.38$ \\
\hline
\end{tabular}

CEC cation exchange capacity, SOM soil organic matter

YRD has experienced three stages. First, large areas of grassland and wilderness with high soil salinity were cultivated with salt-tolerant crops such as cotton, then cereal crops such as maize and rice after soil desalination, and finally vegetables with increasing soil fertility. Therefore, the salinity gradient along with the change in land-use type from vegetable fields to tidal flats corresponds to long-term cultivated soil to newly deposited natural sediments. The SOM content was higher in vegetable fields and wetlands, representing anthropogenic and naturally induced carbon stocks.

Residuals of OCPs in the surface soils

A summary description of mean and range values and detection frequencies for individual OCPs in the surface soils of different land types is presented in
Table 3. The total OCP concentrations ranged from 1.36 to $200.1 \mathrm{\mu g} \mathrm{kg}^{-1}$ with a mean value of $22.7 \mu \mathrm{g} \mathrm{kg}^{-1}$. DDTs and endosulfans were the two most frequent classes of compound followed by HCB and HCHs. The concentrations of DDTs and HCHs were all below the standard value $\left(50 \mu \mathrm{g} \mathrm{kg}^{-1}\right)$ determined by the State Environmental Protection Administration of China (SEPA 1995). However, 17 soil samples have the DDT level (4.2-17.6 $\mu \mathrm{g} \mathrm{kg}^{-1}$ ) higher than the ecological screening value for soil $\left(2.5 \mu \mathrm{g} \mathrm{kg}^{-1}\right)$ recommended by Environmental Protection Agency of the United States (US EPA) (USEPA 2001), and three of these samples (11.1-17.6 $\mu \mathrm{g} \mathrm{kg}^{-1}$ ) even exceed the Dutch target value $\left(10 \mu \mathrm{g} \mathrm{kg}^{-1}\right)$ (NMH 2000). The concentrations of endosulfans in most samples were higher than the Dutch target value for unpolluted soil $\left(0.01 \mu \mathrm{g} \mathrm{kg}^{-1}\right)$, but much lower than the Dutch intervention values 
Table 3 Summary of OCPs in surface soils of different land-use types in the Yellow River Delta ( $\mu \mathrm{g} \mathrm{kg}^{-1} \mathrm{dry}$ weight)

\begin{tabular}{|c|c|c|c|c|c|c|c|c|c|}
\hline \multirow[t]{2}{*}{$\mathrm{OCP}$} & \multicolumn{3}{|c|}{ Vegetable fields $(n=5)$} & \multicolumn{3}{|c|}{ Cereal fields $(n=4)$} & \multicolumn{3}{|c|}{ Cotton fields $(n=13)$} \\
\hline & Mean & Range & $\mathrm{DF}(\%)$ & Mean & Range & $\mathrm{DF}(\%)$ & Mean & Range & $\mathrm{DF}(\%)$ \\
\hline HCB & 0.70 & BDL-1.54 & 80.0 & 1.55 & BDL-2.16 & 75.0 & 1.02 & BDL-3.08 & 76.9 \\
\hline$\alpha-\mathrm{HCH}$ & \multicolumn{3}{|l|}{ BDL } & \multicolumn{3}{|l|}{ BDL } & \multicolumn{3}{|l|}{ BDL } \\
\hline$\beta-\mathrm{HCH}$ & 0.95 & BDL-4.76 & 20.0 & 0.44 & BDL-1.67 & 25.0 & 0.75 & BDL-2.69 & 46.2 \\
\hline$\gamma-\mathrm{HCH}$ & 0.28 & BDL-1.32 & 20.0 & 0.43 & BDL-1.73 & 25.0 & 1.62 & BDL-5.81 & 69.2 \\
\hline$\delta-\mathrm{HCH}$ & \multicolumn{3}{|l|}{ BDL } & \multicolumn{3}{|l|}{ BDL } & \multicolumn{3}{|l|}{ BDL } \\
\hline$\sum \mathrm{HCH}$ & 1.23 & BDL-6.09 & 20.0 & 0.87 & BDL-3.40 & 25.0 & 2.37 & BDL-7.11 & 69.2 \\
\hline$p, p^{\prime}-\mathrm{DDE}$ & 3.10 & BDL-6.66 & 60.0 & 1.88 & BDL-5.16 & 50.0 & 1.61 & BDL-8.49 & 61.5 \\
\hline$p, p^{\prime}$-DDT & 1.91 & $0.46-3.49$ & 100 & 1.64 & $0.51-5.07$ & 100 & 1.48 & BDL-8.84 & 92.3 \\
\hline$o, p^{\prime}$-DDT & 0.91 & BDL-2.05 & 80.0 & 2.48 & BDL-5.15 & 75.0 & 2.35 & BDL-6.71 & 69.2 \\
\hline$o, p^{\prime}-\mathrm{DDD}$ & \multicolumn{3}{|l|}{ BDL } & \multicolumn{3}{|l|}{ BDL } & 0.15 & BDL-1.99 & 7.7 \\
\hline$\sum \mathrm{DDT}$ & 5.91 & $0.46-11.1$ & 100 & 6.02 & $0.61-10.8$ & 100 & 5.60 & $0.60-17.6$ & 100 \\
\hline$\alpha$-Endosulfan & \multicolumn{3}{|l|}{ BDL } & \multicolumn{3}{|l|}{ BDL } & 1.54 & BDL-19.9 & 15.4 \\
\hline$\beta$-Endosulfan & 0.16 & BDL-0.71 & 20.0 & 0.16 & BDL-0.63 & 25.0 & 5.47 & BDL-60.5 & 69.2 \\
\hline Endosulfate & 0.61 & BDL-2.04 & 80.0 & 5.21 & $0.54-18.4$ & 100 & 12.8 & $0.12-80.7$ & 100 \\
\hline$\sum$ Endosulfan & 0.77 & $0.13-2.04$ & 100 & 5.37 & $0.57-18.4$ & 100 & 19.8 & $0.40-161.1$ & 100 \\
\hline Methoxychlor & 0.37 & BDL-1.84 & 20.0 & 1.19 & BDL-1.84 & 75.0 & 2.27 & BDL-11.0 & 53.8 \\
\hline Heptachlor & 0.15 & BDL-0.76 & 20.0 & 0.27 & BDL-1.07 & 25.0 & 0.01 & BDL-0.16 & 7.7 \\
\hline Chlordane & BDL & & & BDL & & & 0.86 & BDL-9.26 & 23.1 \\
\hline Dieldrin & 0.13 & BDL-0.67 & 20.0 & 0.08 & BDL-0.32 & 25.0 & 0.31 & BDL-2.41 & 30.8 \\
\hline Endrin & BDL & & & 3.22 & BDL-12.9 & 25.0 & 1.60 & BDL-8.30 & 23.1 \\
\hline \multirow[t]{2}{*}{$\mathrm{OCP}$} & \multicolumn{3}{|c|}{ Wetlands $(n=4)$} & \multicolumn{3}{|c|}{ Tidal flats $(n=2)$} & \multicolumn{3}{|c|}{ All sites $(n=28)$} \\
\hline & Mean & Range & DF $(\%)$ & Mean & Range & $\mathrm{DF}(\%)$ & Mean & Range & $\mathrm{DF}(\%)$ \\
\hline HCB & 0.38 & BDL-0.73 & 75.0 & 2.07 & BDL-4.09 & 50.0 & 0.99 & BDL-4.09 & 75.0 \\
\hline$\alpha-\mathrm{HCH}$ & BDL & & & BDL & & & BDL & & \\
\hline$\beta-\mathrm{HCH}$ & BDL & & & 0.22 & BDL-0.44 & 50.0 & 0.59 & BDL-4.76 & 32.1 \\
\hline$\gamma-\mathrm{HCH}$ & 0.98 & BDL-1.99 & 50.0 & 1.86 & $1.38-2.33$ & 100 & 1.10 & BDL-5.81 & 53.6 \\
\hline$\delta-\mathrm{HCH}$ & BDL & & & BDL & & & BDL & & \\
\hline$\sum \mathrm{HCH}$ & 0.98 & BDL-1.99 & 50.0 & 2.08 & $1.38-2.78$ & 100 & 1.69 & BDL-7.11 & 53.6 \\
\hline$p, p^{\prime}-\mathrm{DDE}$ & 0.66 & BDL-1.71 & 50.0 & $\mathrm{BDL}$ & & & 1.61 & BDL-8.49 & 53.6 \\
\hline$p, p^{\prime}-\mathrm{DDT}$ & 0.25 & BDL-0.60 & 75.0 & 0.11 & BDL -0.23 & 50.0 & 1.28 & BDL-8.84 & 89.3 \\
\hline$o, p^{\prime}$-DDT & 3.70 & BDL-8.85 & 50.0 & 1.30 & BDL-2.60 & 50.0 & 2.15 & BDL-8.85 & 67.9 \\
\hline$o, p^{\prime}-\mathrm{DDD}$ & 0.01 & BDL & & BDL & & & 0.07 & BDL-1.99 & 3.57 \\
\hline$\sum \mathrm{DDT}$ & 4.62 & BDL-10.4 & 75.0 & 1.42 & $0.23-2.62$ & 100 & 5.11 & BDL-17.6 & 96.4 \\
\hline$\alpha$-Endosulfan & 0.38 & BDL-1.53 & 25.0 & BDL & & & 0.74 & BDL-19.9 & 10.7 \\
\hline$\beta$-Endosulfan & 0.44 & BDL-1.70 & 25.0 & BDL & & & 2.56 & BDL-60.5 & 42.9 \\
\hline Endosulfate & 3.44 & BDL-11.9 & 75.0 & BDL & & & 7.04 & BDL-80.7 & 85.7 \\
\hline$\sum$ Endosulfan & 4.26 & BDL-15.1 & 75.0 & BDL & & & 10.4 & BDL-161.1 & 89.3 \\
\hline Methoxychlor & 2.04 & BDL-7.72 & 50.0 & BDL & & & 1.53 & BDL-11.0 & 46.4 \\
\hline Heptachlor & 0.90 & BDL-2.99 & 50.0 & BDL & & & 0.19 & BDL-2.99 & 17.9 \\
\hline
\end{tabular}


Table 3 continued

\begin{tabular}{|c|c|c|c|c|c|c|c|c|c|}
\hline \multirow[t]{2}{*}{$\mathrm{OCP}$} & \multicolumn{3}{|c|}{ Wetlands $(n=4)$} & \multicolumn{3}{|c|}{ Tidal flats $(n=2)$} & \multicolumn{3}{|c|}{ All sites $(n=28)$} \\
\hline & Mean & Range & $\mathrm{DF}(\%)$ & Mean & Range & $\mathrm{DF}(\%)$ & Mean & Range & $\mathrm{DF}(\%)$ \\
\hline Chlordane & 2.94 & BDL-11.75 & 25.0 & $\mathrm{BDL}$ & & & 0.79 & BDL-11.8 & 14.3 \\
\hline Dieldrin & 1.15 & BDL-4.61 & 25.0 & BDL & & & 0.33 & BDL-4.61 & 25.0 \\
\hline Endrin & 4.13 & BDL-16.5 & 25.0 & BDL & & & 1.73 & BDL-16.5 & 17.9 \\
\hline
\end{tabular}

$B D L$ below detection limit, $D F$ detection frequency (Percentage of samples containing OCPs at a concentration above the detection limit)

(4000 $\left.\mu \mathrm{g} \mathrm{kg}^{-1}\right)(\mathrm{NMH} 2000)$. In addition, concentrations of other measured OCPs (including HCB, dieldrin and endrin) were basically lower than the corresponding ecological screening values of the US EPA (USEPA 2001). Therefore, the soils in this region are unpolluted or slightly polluted by OCPs and suitable for agricultural production.

The highest residual levels of HCHs, DDTs and endosulfans were all found in the samples from cotton fields. The $\gamma-\mathrm{HCH}, o, p^{\prime}$-DDT and endosulfan sulfate predominated the $\mathrm{HCH}$ isomer, DDT and endosulfan metabolites, respectively. This is much different to the results reported in other areas. Zhang et al. (2009) found that $\beta-\mathrm{HCH}$ and $p, p^{\prime}$-DDE were the most abundant components of HCHs and DDTs in soils of the Yangtze River Delta and were mainly derived from the historical residue. The YRD is a coastal region with irrigation mainly from the Yellow River which contains a higher proportion of sediment (Chen et al. 2007). The Yellow River sediment is mainly sourced from soil erosion in the farmland of upstream region (such as in the Loss Plateau); therefore, the organochlorine pesticides might be transported and deposited into the estuarine regions of the YRD by river (Munn and Gruber 1997; Wei et al. 2007). Heptachlor, chlordane, dieldrin and endrin were found at lower detection frequencies, and the highest values were detected in the wetlands. The high concentration of OCPs in the wetland could be caused by river transport as well as the retention of soil organic matter (Gao et al. 2013). Higher organic matter was detected in the soils of wetland (Table 2), which might contribute a lot to the retention of these four OCP species due to their relatively high hydrophobic properties (log $K_{\text {ow }}$ ranged from 5 to 6) (Shoeib and Harner 2002). However, no significant $(p>0.05)$ difference of the OCPs mean concentrations was found between agricultural lands and wetlands.
Compared with previous investigations in cultivated soils from coastal regions (Table 4), the residual levels of DDTs and $\mathrm{HCHs}$ in this study were both lower than those in the Yangtze River Delta and the Pearl River Delta, the two main river deltas in China (Zhang et al. 2009; Yu et al. 2013). $\mathrm{HCH}$ concentrations in the soils were comparable to the data reported in the Xinghua Bay and the IndoGangetic Plain, but slightly higher than on the Liaohe River Plain, three alluvial plains with a longterm history of human cultivation (Zhang et al. 2011b; Teng et al. 2013; Singh et al. 2007). It should be noticed that current levels of endosulfans were much higher than those in Zhejiang and Shanghai agricultural soils and comparable to those in Mexico and Spain (Zhang et al. 2012a, b; Jiang et al. 2009; Cantu-Soto et al. 2011; Plaza-Bolaños et al. 2012).

\section{Possible sources of OCPs}

\section{Spatial distribution}

The spatial distribution of major fractions of DDTs, $\mathrm{HCHs}$ and endosulfans in surface soil of the Yellow River Delta is presented in Fig. 2. HCHs dominated by $\beta$-HCH and $\gamma-\mathrm{HCH}$ showed a wide distribution in soils of the mYRD (Fig. 2a). Da et al. (2013) also observed an elevated level of HCHs in sediments of the Yellow River Estuary. In the case of DDTs, it was noticeable that $p, p^{\prime}$-DDE and $o, p^{\prime}$-DDT presented a contrasting spatial distribution in this region (Fig. 2b). It seems that a higher proportion of $o, p^{\prime}$-DDT was detected mainly inside the $\mathrm{mYRD}$, while a higher proportion of $p, p^{\prime}$-DDE was found outside the mYRD. Dongying City as the core area of the mYRD had not undergone large-scale development until it was founded in 1983 when the use of technical DDT had been banned in 
Table 4 Comparison of OCP residual levels in agricultural surface soils of the Yellow River Delta with the reported levels in other regions ( $\mu \mathrm{g} \mathrm{kg}^{-1}$ dry weight)

\begin{tabular}{llllll}
\hline Region & Sampling year & HCHs & DDTs & Endosulfans & References \\
\hline Yellow River Delta & 2012,2013 & BDL-7.11 & BDL-17.6 & BDL-161.1 & This study \\
Yangtze River Delta & 2003 & $0.28-17.93$ & $0.46-484.2$ & - & Zhang et al. (2009) \\
Pearl River Delta & 2006 & BDL-62 & BDL-110 & - & Yu et al. (2013) \\
Zhejiang & 2006,2007 & & $4.0-529$ & BDL-42 & Zhang et al. (2012a, b) \\
Shanghai & 2007 & BDL-10.4 & $0.44-247.5$ & BDL-4.1 & Jiang et al. (2009) \\
Xinghua Bay & 2009 & $1.22-7.47$ & $0.91-27.9$ & $0.32-11.6$ & Zhang et al. (2011b) \\
Liaohe River Plain & 2010 & $0.70-2.61$ & $1.60-21.6$ & - & Teng et al. (2013) \\
Indo-Gangetic plain & 2003 & $0.08-7.25$ & BDL-74.1 & BDL-13.1 & Singh et al. (2007) \\
Red River Delta & 2006,2007 & - & $1.57-25.4$ & - & Nishina et al. (2010) \\
Southern Sonora, Mexico & 2007 & - & BDL-184.3 & BDL-124 & Cantu-Soto et al. (2011) \\
Almería, Spain & 2011 & - & $15-174$ & $39-222$ & Plaza-Bolaños et al. (2012) \\
\hline
\end{tabular}

$B D L$ below detection limit

China. In contrast, the outer areas of the mYRD, e.g., Binzhou, Zibo and Weifang cities, had longer cultivation histories. The spatial variation between $p, p^{\prime}$ DDE in the delta might indicate the time variation in cultivation development in this area. Moreover, the agricultural runoff and antifouling paints with dicofoltype DDT might induce the higher detection of $o, p^{\prime}$ DDT in the coastal area (Hu et al. 2009). Endosulfan is currently extensively used in agriculture around the world including some food and nonfood crops and has been applied in China to control pests in cotton since 1994 and in wheat, tea, tobacco, apples and other fruits since 1998 (Jia et al. 2009). Accordingly, the highest concentration of endosulfan was detected in the mYRD along the Yellow River dominated by cotton cultivation and was much higher than $\mathrm{HCH}$ and DDT concentrations (Fig. 2c).

\section{Composition of OCPs}

The $\beta-\mathrm{HCH}$ and $p, p^{\prime}$-DDE are more persistent in the environment, and they may accumulate relative to other components in aged technical HCH and DDT; $\gamma$ $\mathrm{HCH}$ and $o, p^{\prime}$-DDT have relatively higher water solubility and have tendency to partition faster from the gas phase into the water phase than other components (Shoeib and Harner 2002). Therefore, percentages of $\mathrm{HCH}$ isomers and DDT metabolites can be an indicator of OCPs source in the environment.
The compositions of HCHs and DDTs were variable among the different land-use types. Percentages of $\beta$ $\mathrm{HCH}$ and $p, p^{\prime}$-DDE clearly decreased in order: vegetable fields $>$ cereal fields $>$ cotton fields $>$ wetlands $>$ tidal flats (except $\beta-\mathrm{HCH}$ in tidal flats, Fig. 3a). Previous studies have found that $\beta-\mathrm{HCH}$ and $p, p^{\prime}$-DDE could be the main residues in farmland soil with longer cultivation history due to the transformation of $\mathrm{HCH}$ and DDT into their stable isomer and metabolite (Zhang et al. 2006; Hu et al. 2010; Gao et al. 2013; Yu et al. 2013). The accumulation of the $\beta$ $\mathrm{HCH}$ and $p, p^{\prime}$-DDE in the cereal and vegetable fields probably resulted from the longer cultivation history of these fields with lower soil salinity. The distribution trend of $\beta-\mathrm{HCH}$ and $p, p^{\prime}$-DDE was consistent with the crop land reclamation in the delta.

Correspondingly, the percentages of $\gamma-\mathrm{HCH}$ and $o, p^{\prime}$-DDT increased in the order: vegetable fields $<$ cereal fields $<$ cotton fields $<$ wetlands $<$ tidal flats (except $\gamma-\mathrm{HCH}$ in tidal flats, Fig. 3b), along with increasing soil salinity. For $\mathrm{HCH}$ isomers, recent studies have showed an elevated level of $\gamma-\mathrm{HCH}$ dominated $\mathrm{HCH}$ isomers in water and sediments in the upstream and downstream of the Yellow River Basin (Wang et al. 2010; Gao et al. 2008; Zhong et al. 2011). For DDT metabolites, high $o, p^{\prime}$-DDT/ $p, p^{\prime}$-DDT ratios have also been reported in river sediments at coastal region of the Bohai Sea, which could be ascribed to the input of dicofol-type DDTs (Da et al. 2014; Wang 

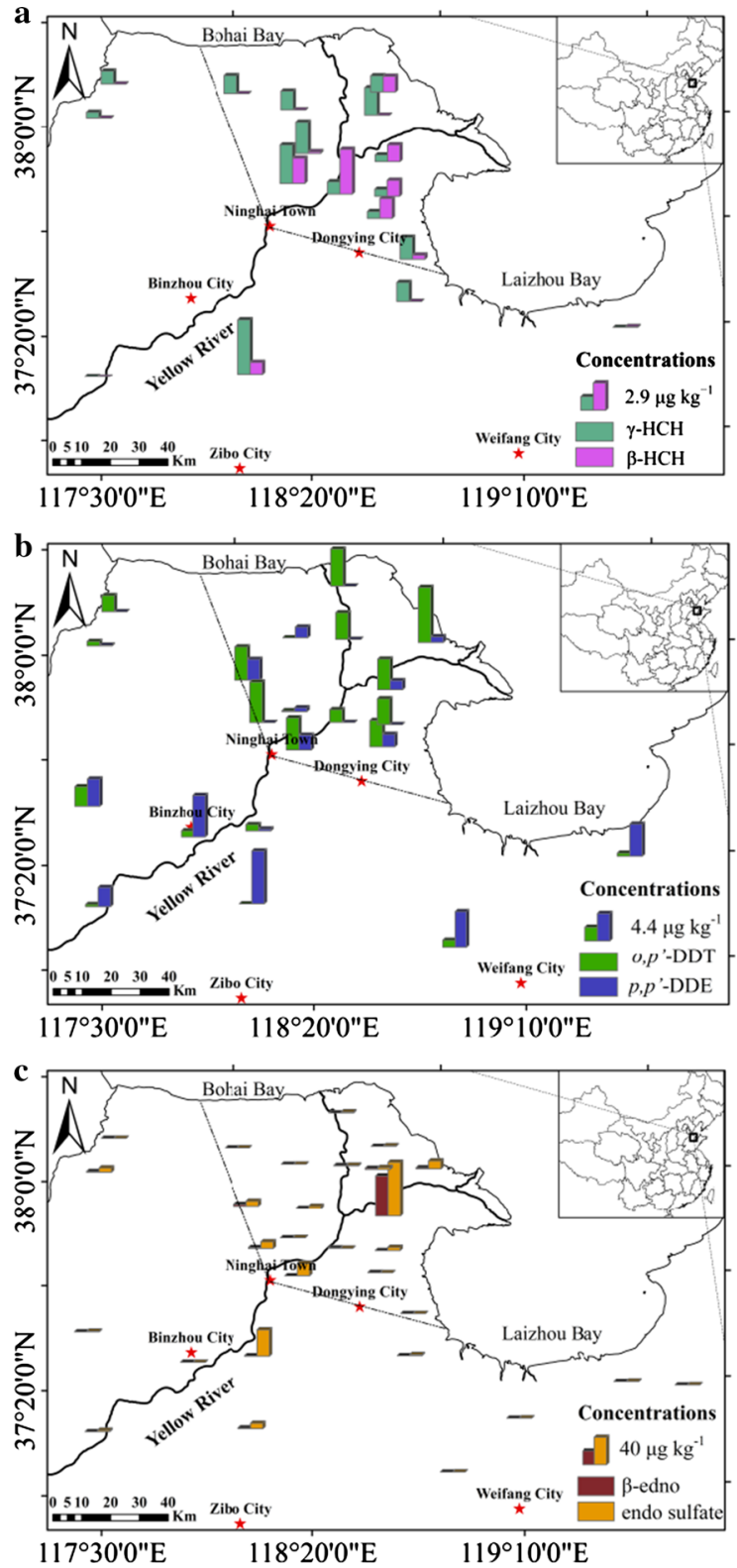

Fig. 2 Spatial distributions of a $\beta-\mathrm{HCH}$ and $\gamma-\mathrm{HCH}$, b $o, p^{\prime}$ DDT and $p, p^{\prime}$-DDE and $\mathbf{c} \beta$-endosulfan and endosulfan sulfate in surface soils of the Yellow River Delta

et al. 2013). The low residual levels of HCHs and DDTs detected in the delta coupled with the relatively high concentrations of $\gamma-\mathrm{HCH}$ and $o, p^{\prime}$-DDT in the water and sediments of upstream and coastal region suggested that the extensively distributed two species (especially $\gamma-\mathrm{HCH}$ ) in the mYRD might be derived from upstream sediments and anthropogenic activities in coastal region. Moreover, a relatively higher level

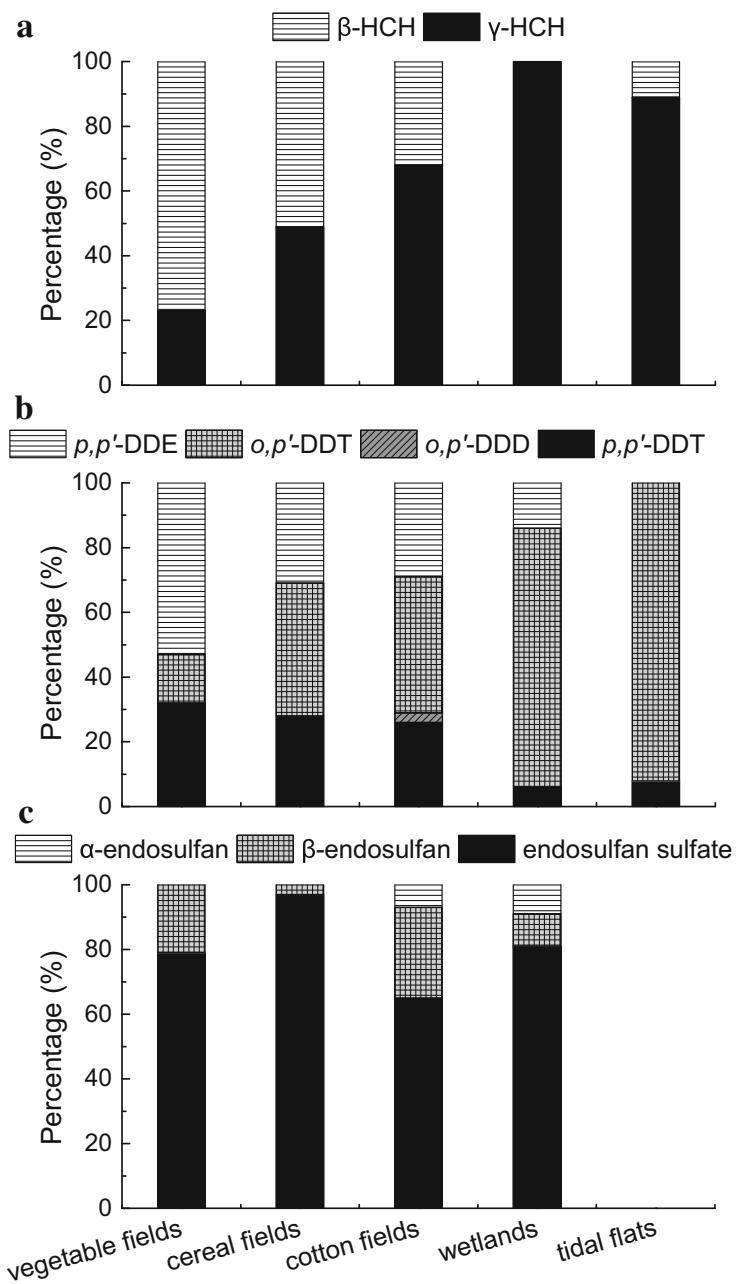

Fig. 3 Composition of individual components of a HCHs, b DDTs and c endosulfans in different land-use types. Endosulfans were not detected in the tidal flats

of $\gamma-\mathrm{HCH}$ and dicofol than other $\mathrm{HCH}$ isomers and DDT metabolites in air of the Bohai Sea was reported by Zhong et al. (2014). Therefore, the atmospheric deposition might also contribute to a portion of OCPs in soils of the YRD.

Endosulfan sulfate was the dominant fraction of endosulfan in the YRD soils, accounting for $59-100 \%$ of the total endosulfan in the samples, followed by $\beta$-endosulfan. None of the endosulfans was detected in tidal flats. The higher frequencies of endosulfan sulfate observed in the samples and the significant correlation between endosulfan sulfate and its parent isomers $(p<0.05)$ implied endosulfan sulfate mainly originated from its parent isomers. 
The higher concentrations of endosulfan observed in cotton fields and wetland sites close to the coast might be mainly influenced by the cotton production and agricultural runoff.

\section{Influence of soil properties}

Soil properties (SOM, clay content and salinity) play an important role in the distribution and composition of OCPs. SOM is usually assumed to have the greatest effect on the adsorption of OCPs in natural soils because of their hydrophobicity (Gao et al. 2013). Kannan et al. (2003) reported that residual levels of OCPs were proportional to SOM for a soil-air system in equilibrium. The positive correlation between $\beta$ $\mathrm{HCH}$ and SOM suggested that the $\beta-\mathrm{HCH}$ approached the adsorption equilibrium status with SOM (Fig. 4a). Clay content was positively correlated with $\gamma-\mathrm{HCH}$ (Fig. 4b). Cotransport of the organochlorine chemicals with suspended sediments or eroded soils from upstream to downstream in a river basin has been reported by numerous previous studies (Herrmann and
Thomas 1984; Lee et al. 2001; Munn and Gruber 1997). The $\gamma-\mathrm{HCH}$ as dominated $\mathrm{HCH}$ isomer in the upstream of Yellow River with a low concentration in the YRD soil implied the sediment input from Yellow River might be the main source of the OCPs in the delta compared to the anthropogenic activity (Wang et al. 2010; Gao et al. 2008).

$\mathrm{Hu}$ et al. (2009) reported agricultural dicofol application, chemical plants effluent and the usage of DDT for antifouling paints together lead to the elevated DDT concentrations in sediments at coastal area of Bohai Sea. Salinity was positively correlated with $o, p^{\prime}$-DDT (Fig. 4c). The higher contents of $o, p^{\prime}$ DDT toward estuary area with higher soil salinity were likely associated with the agricultural runoff from dicofol application and usage of DDT-containing antifouling paints. However, a significantly negative correlation was found between $p, p^{\prime}$-DDE and salinity in the region (Fig. 4d). The agro-labor population density mapped by Zhang et al. (2011a) decreased from inland to coast in the YRD. The lower level of agricultural activities in the area with higher soil
Fig. 4 Relationship between soil properties and OCPs. a The relationship between SOM and $\beta-\mathrm{HCH}$ ( 8 out of 9 points); $\mathbf{b}$ the relationship between clay content and $\gamma$-HCH (12 out of 15 points); $\mathbf{c}$ the relationship between salinity and $o, p^{\prime}$-DDT; and d the relationship between salinity and $p, p^{\prime}$-DDE
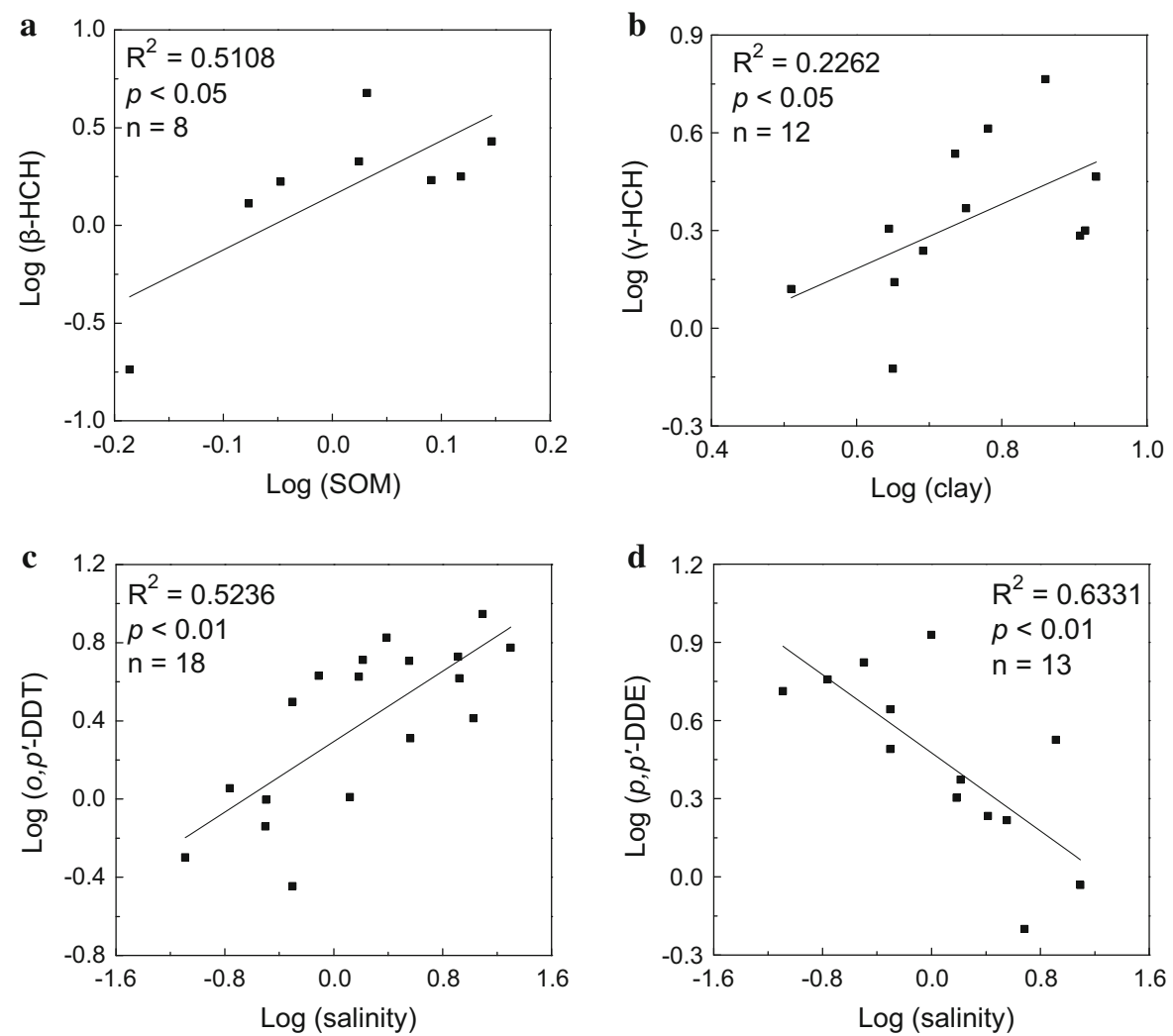
salinity might thus be a determinant for the $p, p^{\prime}$-DDE decrease toward the coast. Previous studies have reported that high salinity either partially or completely inhibits microbial methanogenesis and aryl dechlorination of organochlorine compounds (Allard et al. 1992; Cho and Oh 2005; Rinzema et al. 1988). The inhibition of microbial degradation of DDTs in the coastal soils might be another potential factor contributed to DDTs residues, but further experiments would be needed to prove that.

Depth distributions of OCPs in cotton fields

Soil profile samples are capable of providing information on the historical deposition of organic pollutants. Six soil profiles in cotton fields were chosen to explain the depth distribution and source of $\mathrm{HCHs}$, DDTs and endosulfans (Fig. 5). Mean concentrations of $\sum \mathrm{HCH}, \sum \mathrm{DDT}$ and $\sum$ endosulfan were all below $3.0 \mu \mathrm{g} \mathrm{kg}^{-1}$ in the soil profiles, indicating there was not obviously fresh application of OCPs into these soils. $\gamma$-HCH predominated in the soil profiles and also showed a positive correlation $(p<0.05$, data not show) with the clay content. The results might further confirm the cotransport of the OCPs with the Yellow River sediment. $\beta-\mathrm{HCH}$ increased slightly with depth from the topsoil to the basal soil horizon, indicating historical application of HCHs. DDT metabolites showed a homogeneous composition in the topsoil, while $o, p^{\prime}$-DDT and $p, p^{\prime}$-DDT dominated the horizons beneath. Previous studies also reported elevated levels of $o, p^{\prime}$-DDT and $p, p^{\prime}$-DDT in sediments of the Old Yellow River Estuary and Laizhou Bay, respectively
(Da et al. 2014; Zhong et al. 2011). The high $o, p^{\prime}$-DDT and $p, p^{\prime}$-DDT percentage in the YRD soil profiles might indicate the residue of technical DDTs and dicofol DDTs mixture. Endosulfan sulfate was the major transformation product of endosulfan under aerobic conditions (Martens 1977). $\beta$-Endosulfan predominated in the deeper soil horizons though endosulfan sulfate was the most frequently detected metabolite in topsoil, and this might imply a lower transformation rate of endosulfan in basal soil horizons and a longer application history of endosulfan.

\section{Conclusions}

The present study has provided the first report on the residual levels of OCPs in the soils of the Yellow River Delta region and shows low levels of OCP residues in the soils together with elevated endosulfan concentrations in some cotton fields. HCHs, DDTs, endosulfans and HCB were detected in most of the soil samples with a concentration sequence of endosulfans $>$ DDTs $>$ HCHs $>$ HCB. The spatial distribution and composition of HCHs and DDTs were variable, particularly with land-use types along a salinity gradient. In the case of $\mathrm{HCH}$ isomers and DDT metabolites, the percentages of $\gamma-\mathrm{HCH}$ and $o, p^{\prime}$-DDT increased with soil salinity. These two species that distributed widely in the coastal area had a high affinity with clay content and salinity, respectively. Residues of $\beta-\mathrm{HCH}$ had a positive relationship with the contents of SOM. In addition, soil salinity was supposed to be a major factor to influence the fate of DDT and DDE in the delta soils.
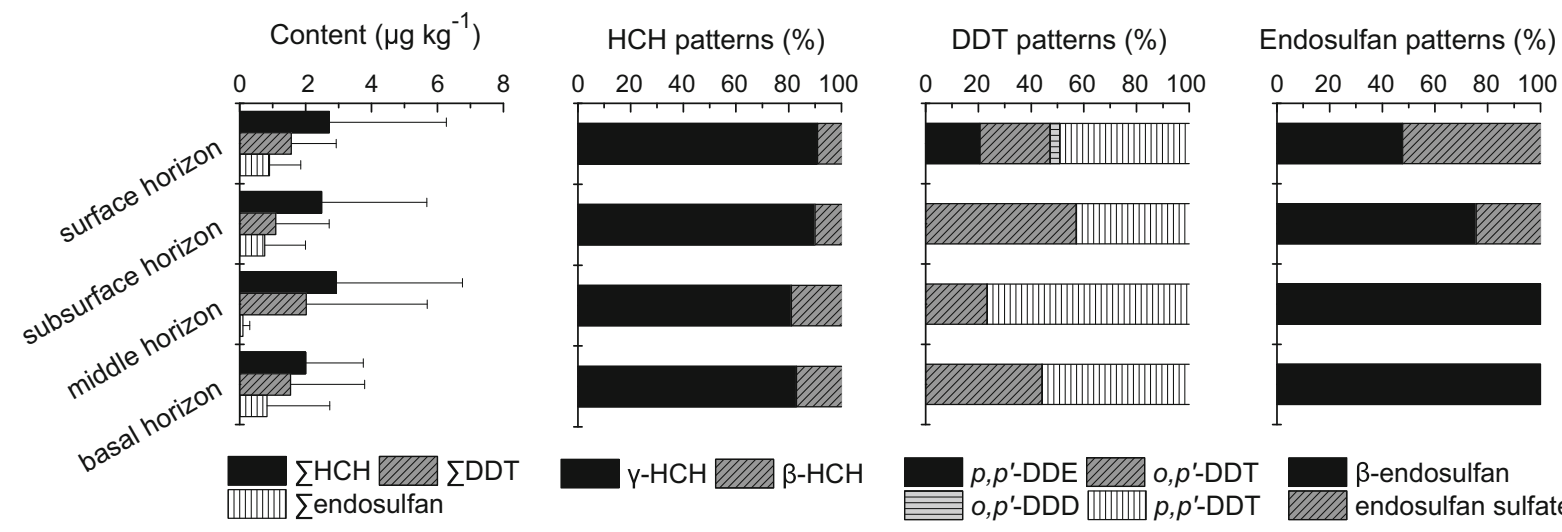

Fig. 5 Concentrations of $\sum \mathrm{HCH}, \sum \mathrm{DDT}$ and $\sum$ endosulfan and distribution patterns of their components in soil profiles from cotton fields 
Depth distribution of the OCPs in some typical soil profiles further confirmed their possible sources in the YRD, which could be mainly attributed to the parent OCPs residue with lower transformation rate and sediment cotransport by the Yellow River.

Acknowledgments The authors are grateful for the financial support from the Science and Technology Development Program of Yantai (2013ZH080), the National Natural Science Foundation of China (NSFC) (41371313, 41230858) and the Key Research Program of the Chinese Academy of Sciences (KZZD-EW-14).

\section{References}

Allard, A. S., Hynning, P. A., Remberger, M., \& Neilson, A. H. (1992). Role of sulfate concentration in dechlorination of 3,4,5-trichlorocatechol by stable enrichment cultures grown with coumarin and flavanone glycones and aglycones. Applied and Environmental Microbiology, 58(3), 961-968.

Boul, H. L., Garnham, M. L., Hucker, D., Baird, D., \& Aislable, J. (1994). Influence of agricultural practices on the levels of DDT and its residues in soil. Environmental Science and Technology, 28(8), 1397-1402.

Cantu-Soto, E. U., Meza-Montenegro, M. M., ValenzuelaQuintanar, A. I., Félix-Fuentes, A., Grajeda-Cota, P., Balderas-Cortes, J. J., et al. (2011). Residues of organochlorine pesticides in soils from the Southern Sonora, Mexico. Bulletin of Environmental Contamination and Toxicology, 87(5), 556-560.

Chen, J., Taniguchi, M., Liu, G., Miyaoka, K., Onodera, S., Tokunaga, T., \& Fukushima, Y. (2007). Nitrate pollution of groundwater in the Yellow River delta, China. Hydrogeology Journal, 15(8), 1605-1614.

Cho, Y. C., \& Oh, K. H. (2005). Effects of sulfate concentration on the anaerobic dechlorination of polychlorinated biphenyls in estuarine sediments. Journal of Microbiology, 43(2), 166-171.

Da, C. N., Liu, G. J., Tang, Q., \& Liu, J. J. (2013). Distribution, sources, and ecological risks of organochlorine pesticides in surface sediments from the Yellow River Estuary, China. Environmental Science: Processes \& Impacts, 15(12), 2288-2296.

Da, C. N., Liu, G. J., \& Yuan, Z. J. (2014). Analysis of HCHs and DDTs in a sediment core from the Old Yellow River Estuary, China. Ecotoxicology and Environmental Safety, 100, 171-177.

FAO, IUSS Working Group WRB. (2007). World reference base for soil resources 2006, first update 2007. World Soil Resources Reports No. 103. FAO, Rome.

Gao, J., Liu, L., Liu, X., Lu, J., Zhou, H., Huang, S., et al. (2008). Occurrence and distribution of organochlorine pesticides-Lindane, p, p'-DDT, and heptachlor epoxide-In surface water of China. Environment International, 34(8), 1097-1103.
Gao, F., Luo, X. J., Yang, Z. F., Wang, X. M., \& Mai, B. X. (2009). Brominated flame retardants, polychlorinated biphenyls, and organochlorine pesticides in bird eggs from the Yellow River Delta, north China. Environmental Science and Technology, 43(18), 6956-6962.

Gao, J., Zhou, H., Pan, G., Wang, J., \& Chen, B. (2013). Factors influencing the persistence of organochlorine pesticides in surface soil from the region around the Hongze Lake, China. Science of the Total Environment, 443, 7-13.

Herrmann, R., \& Thomas, W. (1984). Behaviour of some PAH, PCB and organochlorine pesticides in an estuary, a comparison-Exe, Devon. Fresenius' Zeitschrift für analytische Chemie, 319(2), 152-159.

Hu, W. Y., Lu, Y. L., Wang, T. Y., Luo, W., Shi, Y. J., Giesy, J. P., et al. (2010). Spatial variability and temporal trends of $\mathrm{HCH}$ and DDT in soils around Beijing Guanting Reservoir, China. Environmental Geochemistry and Health, 32(5), 441-449.

Hu, L., Zhang, G., Zheng, B., Qin, Y., Lin, T., \& Guo, Z. (2009). Occurrence and distribution of organochlorine pesticides (OCPs) in surface sediments of the Bohai Sea, China. Chemosphere, 77(5), 663-672.

Iwata, H., Tanabe, S., Sakai, N., Nishimura, A., \& Tatsukawa, R. (1994). Geographical distribution of persistent organochlorines in air, water and sediments from Asia and Oceania, and their implications for global redistribution from lower latitudes. Environmental Pollution, 85(1), 15-33.

Jia, H. L., Li, Y. F., Wang, D., Cai, D., Yang, M., Ma, J., \& Hu, J. (2009). Endosulfan in China $1-$ Gridded usage inventories. Environmental Science and Pollution Research, 16(3), 295-301.

Jia, H. L., Liu, L. Y., Sun, Y. Q., Sun, B., Wang, D. G., Su, Y. S., et al. (2010). Monitoring and modeling endosulfan in Chinese surface soil. Environmental Science and Technology, 44(24), 9279-9284.

Jiang, Y. F., Wang, X. T., Jia, Y., Wang, F., Wu, M. H., Sheng, G. Y., \& Fu, J. M. (2009). Occurrence, distribution and possible sources of organochlorine pesticides in agricultural soil of Shanghai, China. Journal of Hazardous Materials, 170(2-3), 989-997.

Kannan, K., Battula, S., Loganathan, B. G., Hong, C. S., Lam, W. H., Villeneuve, D. L., et al. (2003). Trace organic contaminants, including toxaphene and trifluralin, in cotton field soils from Georgia and South Carolina, USA. Archives of Environmental Contamination and Toxicology, 45(1), 30-36.

Lee, K. T., Tanabe, S., \& Koh, C. H. (2001). Distribution of organochlorine pesticides in sediments from Kyeonggi Bay and nearby areas, Korea. Environmental Pollution, 114(2), 207-213.

Lu, R. K. (1999). Soil and agricultural chemical analysis methods. Beijing: Chinese Agricultural Science and Technology. (in Chinese).

Martens, R. (1977). Degradation of endosulfan-8, 9-14C in soil under different conditions. Bulletin of Environmental Contamination and Toxicology, 17(4), 438-446.

Munn, M. D., \& Gruber, S. J. (1997). The relationship between land use and organochlorine compounds in streambed sediment and fish in the Central Columbia Plateau, 
Washington and Idaho, USA. Environmental Toxicology and Chemistry, 16(9), 1877-1887.

Nishina, T., Kien, C. N., Noi, V. N., Ngoc, H. M., Kim, C. S., Tanaka, S., \& Iwasaki, K. (2010). Pesticide residues in soils, sediments, and vegetables in the Red River Delta, northern Vietnam. Environmental Monitoring and Assessment, 169(1-4), 285-297.

Plaza-Bolaños, P., Padilla-Sánchez, J. A., Garrido-Frenich, A., Romero-González, R., \& Martínez-Vidal, J. L. (2012). Evaluation of soil contamination in intensive agricultural areas by pesticides and organic pollutants: South-eastern Spain as a case study. Journal of Environmental Monitoring, 14(4), 1181-1188.

Qiu, X. H., Zhu, T., Yao, B., Hu, J. X., \& Hu, S. W. (2005). Contribution of dicofol to the current DDT pollution in China. Environmental Science and Technology, 39(12), 4385-4390.

Rinzema, A., Van Lier, J., \& Lettinga, G. (1988). Sodium inhibition of acetoclastic methanogens in granular sludge from a UASB reactor. Enzyme and Microbial Technology, 10(1), 24-32.

Shoeib, M., \& Harner, T. (2002). Using measured octanol-air partition coefficients to explain environmental partitioning of organochlorine pesticides. Environmental Toxicology and Chemistry, 21(5), 984-990.

Singh, K. P., Malik, A., \& Sinha, S. (2007). Persistent organochlorine pesticide residues in soil and surface water of northern Indo-Gangetic alluvial plains. Environmental Monitoring and Assessment, 125(1-3), 147-155.

State Environmental Protection Administration (SEPA). (1995). Environmental quality standard for soils. SEPA, China GB15618-1995. (in Chinese).

Tao, S., Liu, W., Li, Y., Yang, Y., Zuo, Q., Li, B., \& Cao, J. (2008). Organochlorine pesticides contaminated surface soil as reemission source in the Haihe Plain, China. Environmental Science and Technology, 42(22), 8395-8400.

Teng, M., Zhang, H. J., Fu, Q., Lu, X. B., \& Chen, J. P. (2013). Irrigation-induced pollution of organochlorine pesticides and polychlorinated biphenyls in paddy field ecosystem of Liaohe River Plain, China. Chinese Science Bulletin, 58(15), 1751-1759.

The Netherlands Ministry of Housing (NMH). (2000). Spatial planning and environment's circular on target values and intervention values for soil remediation. NMH, Dutch. http://www.esdat.net/Environmental\%20Standards/Dutch/ annexS_I2000Dutch\%20Environmental\%20Standards.pdf

US Environmental Protection Agency (USEPA). (2001). Recommended ecological screening values for soil. USEPA, USA. http://www.epa.gov/region4/superfund/images/ allprogrammedia/pdfs/tsstablesoilvalues.pdf.

Wang, L., Jia, H. L., Liu, X. J., Sun, Y. Q., Yang, M., Hong, W. J., et al. (2013). Historical contamination and ecological risk of organochlorine pesticides in sediment core in northeastern Chinese river. Ecotoxicology and Environmental Safety, 93, 112-120.
Wang, G., Ma, L., Sun, J., \& Zhang, G. (2010). Occurrence and distribution of organochlorine pesticides (DDT and $\mathrm{HCH}$ ) in sediments from the middle and lower reaches of the Yellow River, China. Environmental Monitoring and Assessment, 168(1-4), 511-521.

Wei, D., Kamey, T., \& Urano, K. (2007). Environmental management of pesticidal POPs in China: Past, present and future. Environment International, 33(7), 894-902.

Wong, M. H., Leung, A. O. W., Chan, J. K. Y., \& Choi, M. P. K. (2005). A review on the usage of POP pesticides in China: With emphasis on DDT loadings in human milk. Chemosphere, 60(6), 740-752.

Yu, H. Y., Li, F. B., Yu, W. M., Li, Y. T., Yang, G. Y., Zhou, S. G., et al. (2013). Assessment of organochlorine pesticide contamination in relation to soil properties in the Pearl River Delta, China. Science of the Total Environment, 447, 160-168.

Zhang, A. P., Chen, Z. Y., Ahrens, L., Liu, W. P., \& Li, Y. F. (2012a). Concentrations of DDTs and enantiomeric fractions of chiral DDTs in agricultural soils from Zhejiang Province, China, and correlations with total organic carbon and pH. Journal of Agricultural and Food Chemistry, 60(34), 8294-8301.

Zhang, A. P., Fang, L., Wang, J. L., Liu, W. P., Yuan, H. J., Jantunen, L., \& Li, Y. F. (2012b). Residues of currently and never used organochlorine pesticides in agricultural soils from Zhejiang Province, China. Journal of Agricultural and Food Chemistry, 60(12), 2982-2988.

Zhang, H. B., Luo, Y. M., \& Li, Q. B. (2009). Burden and depth distribution of organochlorine pesticides in the soil profiles of Yangtze River Delta Region, China: Implication for sources and vertical transportation. Geoderma, 153(1-2), 69-75.

Zhang, H. B., Luo, Y. M., Zhao, Q. G., Wong, M. H., \& Zhang, G. L. (2006). Residues of organochlorine pesticides in Hong Kong soils. Chemosphere, 63(4), 633-641.

Zhang, J. Q., Qi, S. H., Xing, X. L., Tan, L. Z., Gong, X. Y., Zhang, Y., \& Zhang, J. P. (2011b). Organochlorine pesticides (OCPs) in soils and sediments, southeast China: A case study in Xinghua Bay. Marine Pollution Bulletin, 62(6), 1270-1275.

Zhang, T. T., Zeng, S. L., Gao, Y., Ouyang, Z. T., Li, B., Fang, C. M., \& Zhao, B. (2011a). Assessing impact of land uses on land salinization in the Yellow River Delta, China using an integrated and spatial statistical model. Land Use Policy, 28(4), 857-866.

Zhong, G. C., Tang, J. H., Xie, Z. Y., Möller, A., Zhao, Z., Sturm, R., et al. (2014). Selected current-use and historicuse pesticides in air and seawater of the Bohai and Yellow Seas, China. Journal of Geophysical Research: Atmospheres, 119(2), 1073-1086.

Zhong, G. C., Tang, J. H., Zhao, Z., Pan, X. H., Chen, Y. J., Li, J., \& Zhang, G. (2011). Organochlorine pesticides in sediments of Laizhou Bay and its adjacent rivers, North China. Marine Pollution Bulletin, 62(11), 2543-2547. 